\title{
Comment to "Bronchial asthma control degree and the temperament structure according to the Eysenck model"
}

\author{
Serdar Kalemci' ${ }^{1}$, Aydın Sarıhan ${ }^{2}$, Nihat Taşdemir ${ }^{3}$, Arife Zeybek ${ }^{4}$ \\ 1Department of Chest Diseases, Medical Park Gebze Hospital, Kocaeli, Turkey \\ ${ }^{2}$ Department of Emergency Medicine, Manisa City Hospital, Manisa, Turkey \\ ${ }^{3}$ Department of Radiology, Medical Park Gebze Hospital, Kocaeli, Turkey \\ ${ }^{4}$ Department of Chest Surgery, School of Medicine, Muğla Sıtkı Koçman University, Muğla, Turkey
}

Adv Dermatol Allergol 2021; XXXVIII (2): 349

DOI: https://doi.org/10.5114/ada.2021.106219

We have read with great interest the article recently published by Witusik et al. entitled "Bronchial asthma control degree and the temperament structure according to the Eysenck model" [1].

In this study, we would like to point to some important issues. The authors of this study have suggested that the structure of temperament of a person with poor control of bronchial asthma can be characterized. The correct use of the inhaler drugs, the patient-physician cooperation and the patient compliance are crucial points in success of the asthma treatment. The controls ensure that the patient uses the inhaler drugs correctly. Inappropriate use of the inhaler drugs is the most important reason for failure in asthma treatment [2]. In this study, we did not see any information relevant to the evaluation of inhaler drugs use of the patients. Gastroesophageal reflux (GER) may provoke coughing and wheezing and also may increase the symptoms in patients. When compared with the general population, GER is three times more common in patients with asthma. Reflux should be considered even though there are no typical complaints of reflux in patients with nocturnal symptoms and whose asthma is not under control [3]. The authors do not mention the presence of GER in the groups. In addition, pregnancy may have an adverse impact on asthma control [4]. Did you apply any questionnaire about pregnancy?

\section{Conflict of interest}

The authors declare no conflict of interest.

\section{References}

1. Witusik A, Mokros Ł, Kuna P, Pietras T. Bronchial asthma control degree and the temperament structure according to the Eysenck model. Adv Dermatol Allergol 2020; 27: 559-65.

2. Usmani OS. Choosing the right inhaler for your asthma or COPD patient. Ther Clin Risk Manag 2019; 15: 461-72.

3. Diette GB, Krishnan JA, Dominici F, et al. Asthma in older patients: factors associated with hospitalization. Arch Intern Med 2002; 162: 1123-32.

4. Maselli DJ, Adams SG, Peters JI, Levine SM. Management of asthma during pregnancy. Ther Adv Respir Dis 2013; 7: 87-100.

Address for correspondence: Aydın Sarıhan, Department of Emergency Medicine, Manisa City Hospital, 45506 Sehsadeler, Manisa, Turkey, phone: +90 544 8877117, e-mail: aydinsarihan@yahoo.com Received: 17.05.2019, accepted: 28.07.2019. 